\title{
Evaluation of the Adsorption of Hexavalent Chromium on Kaolinite and Illite
}

\author{
Omar Ajouyed, Charlotte Hurel, Nicolas Marmier \\ Institute of Chemistry of Nice, Faculty of Science, University of Nice Sophia Antipolis, Nice, France. \\ E-mail: o.ajouyed@hotmail.com
}

Received September 21 ${ }^{\text {st }}, 2011$; revised October $23^{\text {rd }}, 2011$; accepted November $28^{\text {th }}, 2011$.

\begin{abstract}
The adsorption of hexavalent chromium on Kaolinite and Illite was studied in order to evaluate their potential for the reduction of hexavalent chromium mobility and their possible application for the treatment of polluted sediment. The influence of various parameters affecting the adsorption of hexavalent chromium, such as the $\mathrm{pH}$ of aqueous solution, the ionic strength and the initial metal ion concentration were investigated. The optimal $\mathrm{pH}$ range corresponding to the hexavalent chromium adsorption maximum on the Kaolinite and Illite is $2-4$ and $2-2.6$, respectively. The results showed that hexavalent chromium sorption on Kaolinite and Illite was strongly influenced by the $\mathrm{pH}$, the ionic strength and the initial metal ion concentration. Langmuir and Freundlich adsorption isotherms are employed to understand the nature of adsorption at room temperature. The characteristic parameters for each isotherm have been determined. This showed that the Freundlich isotherm model well described the equilibrium data. The data suggest that the charge of the clay mineral surface is one of the main factors controlling hexavalent chromium desorption at alkaline pHs.
\end{abstract}

Keywords: Hexavalent Chromium, Clay Mineral, Sediment, Adsorption, Stabilization

\section{Introduction}

Heavy-metal concentrations in aquatic ecosystems, especially chromium, have increased considerably as a result of inputs from human production and consumption activities. In the ecosystem, sediments are the main sink for these elements, but when environmental conditions change ( $\mathrm{pH}$, redox potential, etc.), sediments can act as a source of metals. Sediments contaminated with heavy metals have the potential to impart adverse effects to aquatic organisms and contribute to the degradation of ecosystem function. Sediment accumulation in ports and other waterways requires dredging to maintain navigation. If dredged sediments are contaminated, it is therefore necessary to propose appropriate treatment techniques that satisfy environmental as well as economic criteria.

Chromium is a common pollutant found in industrial effluents; chromium salts are extensively used in several industrial processes such as tanneries, electroplating, textile, dyeing, and metal finishing industries. Chromium is found in various oxidation states ranging from $-\mathrm{II}$ to $+\mathrm{VI}$. Trivalent $[\mathrm{Cr}(\mathrm{III})]$ and hexavalent $[\mathrm{Cr}(\mathrm{VI})]$ chromium are of major environmental significance depending on $\mathrm{pH}$ and redox conditions [1,2]. As an hexavalent chromium anions are highly mobile in sediment, soil and water en- vironments. Trivalent chromium, on the other hand, is known to be essential for protein, lipid and glucose metabolism of mammals. Trivalent chromium is a cationic species and is rather immobile due to its low solubility, high adsorption and complexation. Due to the severe toxicity of hexavalent chromium, the Agency for Toxic Substances and Diseases Registry classifies it as the top sixteenth hazardous substance [3]. Indicative limits for total chromium concentrations in drinking water and reclaimed wastewater for irrigation are 0.05 [4] and $0.1-1$ $\mathrm{mg} / \mathrm{L}$ [5], respectively.

Clay minerals are hydrous aluminosilicates broadly defined as those minerals that make up the colloid fraction $(<2 \mu)$ of soils, sediments, etc. and may be composed of mixtures of fine grained clay minerals and clay-sized crystals of other minerals such as quartz, carbonate and metal oxides. Usually the term clay mineral is used for materials that become plastic when mixed with a small amount of water. Clay minerals play an important role in the environment by acting as a natural scavenger of pollutants by taking up cations and anions which are toxic to human and wildlife even at very low concentrations. Clay minerals have been widely used in a range of applications because of either high cation exchange capacity, swelling 
capacity, high specific surface area, and consequential strong adsorption capacity [6]. Kaolinite and Illite are two of the most important mineral components in crystalline and sedimentary rock formations as far as adsorption is concerned. For this reason we have decided to study these clay minerals and to investigate, qualify and quantify their role in the immobilization of metals in a polluted sediment.

The aim of this work is to examine the hexavalent chromium ions adsorption behavior from aqueous solution on commercial adsorbents (Kaolinite and Illite) by a batch method as a function of the $\mathrm{pH}$, ionic strength and initial metal ion concentration of the solution. Adsorption isotherms have been analysed in terms of Langmuir and Freundlich equations. This study falls under the context of the management of dredged sediments, and focus on the mineralogical fraction which could accumulate anionic species of metals in a polluted sediment.

\section{Materials}

The Kaolinite and Illite (Illite du Puy) used in this study come from Sigma-Aldrich and the region of Le Puy-enVelay, France, repectively. These adsorbent materials were chosen on the basis of their availability, potential efficiency and market-price.

A stock solution containing hexavalent chromium ions was prepared from the analytical grade $\mathrm{K}_{2} \mathrm{Cr}_{2} \mathrm{O}_{7}$ (SigmaAldrich, purity equal to $99.5 \%$ ) in ultrapure water. $\mathrm{NaNO}_{3}$ was used as the supporting electrolyte to maintain the ionic strength constant during the adsorption experiments. Solutions of $(0.01,0.1$ and $1 \mathrm{M}) \mathrm{NaOH}$ and $\mathrm{HNO}_{3}$ were used for $\mathrm{pH}$ adjustment. The $\mathrm{pH}$ of the solutions was measured using a Consort $\mathrm{pH}$ meter C 561, calibrated using buffer solutions at $\mathrm{pH} 4.00$ and 7.00 at room temperature. Chromium concentrations in the supernatant were determined by Inductively Coupled Plasma-Optical Emission Spectrometry (ICP-OES). The content (\%) of hexavalent chromium adsorbed by solid was determined from the difference between initial $C_{i}$ and final $C_{f}$ concentrations of hexavalent chromium ion in aqueous solution, before and after contact. The following equation was used for calculations:

$$
\% \mathrm{Cr}(\mathrm{VI}) \text { Adsorbed }=\left(\frac{C_{i}-C_{f}}{C_{i}}\right) \times 100
$$

\section{Batch Adsorption Experiments}

All adsorption experiments were conducted in $50 \mathrm{~mL}$ polypropylene tubes at room temperature by using batch technique. The effect of solution $\mathrm{pH}$ (range 2 - 11), ionic strength $(0.01,0.05$ and $0.1 \mathrm{M})$ and initial $\mathrm{Cr}(\mathrm{VI})$ concentrations $(0.1$ and $0.5 \mathrm{mg} / \mathrm{L})$ on the adsorption were studied. A constant mass $(0.2 \mathrm{~g})$ of Kaolinite or Illite was equilibrated with chromium solution in the presence of sodium nitrate. A small amount of acid or base was added to the dispersions to fix $\mathrm{pH}$. The dispersions were continuously stirred during $24 \mathrm{~h}$, centrifuged at $4000 \mathrm{rpm}$ for $15 \mathrm{~min}$, filtered through $0.45 \mu \mathrm{m}$ pore size acetate filters, acidified, and analysed for metal ion concentrations.

The adsorption isotherms were determined by a batch technique in a background electrolyte of $0.01 \mathrm{M} \mathrm{NaNO}_{3}$. In the experiments, $0.2 \mathrm{~g}$ of Kaolinite or Illite were mixed with $50 \mathrm{~mL}$ solutions of various hexavalent chromium concentrations between $0.1 \mathrm{mg} / \mathrm{L}$ and $16 \mathrm{mg} / \mathrm{L}$. The $\mathrm{pH}$ of the system was maintained at 8 , characteristic of the $\mathrm{pH}$ value for sediment equilibrated with water. After that, the samples were shaken, the dispersions were centrifuged, filtered and acidified for later analyses of anion concentration.

\section{Results and Discussion}

Hexavalent chromium exists in solution as chromic acid $\left(\mathrm{H}_{2} \mathrm{CrO}_{4}\right)$, dichromate $\left(\mathrm{Cr}_{2} \mathrm{O}_{7}^{2-}\right)$, bichromate $\left(\mathrm{HCrO}_{4}^{-}\right)$or chromate $\left(\mathrm{CrO}_{4}^{2-}\right)$ depending on the $\mathrm{pH}$ and the hexavalent chromium concentration [7]. The $\mathrm{pH}$ and concentration ranges were used in this study meant that bichromate $\left(\mathrm{HCrO}_{4}^{-}\right)$in an acidic medium and chromate $\left(\mathrm{CrO}_{4}^{2-}\right)$ in an neutral and basic medium would be the predominant form of hexavalent chromium which participate in adsorption [8]. For practical reasons, the hexavalent chromium writing will be used for both chromates and bichromates.

\subsection{Effet of Solution $\mathbf{p H}$}

The $\mathrm{pH}$ of the solution is one of the prime factors that drastically influence the adsorption behavior of a system. In the present studies, the effect of $\mathrm{pH}$ has been observed by varying the $\mathrm{pH}$ of the dispersion in the range $2-11$. The results are depicted in Figure 1, which clearly reveal that the optimum adsorption is at $\mathrm{pH} \leq 4$ for Kaolinite and $\mathrm{pH} \leq 2.6$ for Illite while the adsorption of hexavalent chromium decreases as solution $\mathrm{pH}$ increased.

It is generally accepted that clay minerals possess two distinctly different surfaces, that of the basal faces, which possesses charge arising from isomorphous substitution within both tetrahedral and octahedral sheets (e.g., $\mathrm{Al}^{3+}$ for $\mathrm{Si}^{4+}$ in tetrahedral coordination, or $\mathrm{Mg}^{2+}$ for $\mathrm{Al}^{3+}$ in octahedral coordination), and that of the broken bond surface at the edge. These surfaces are expected to the adsorption process for cations and anions by cation exchange and a surface complexation $[9,10]$. In our case, surface complexation at amphoteric edge sites $(\equiv \mathrm{SOH})$ is expected to be the most relevant adsorption process for chromium.

In aqueous systems, the surface groups of the clay mi- 


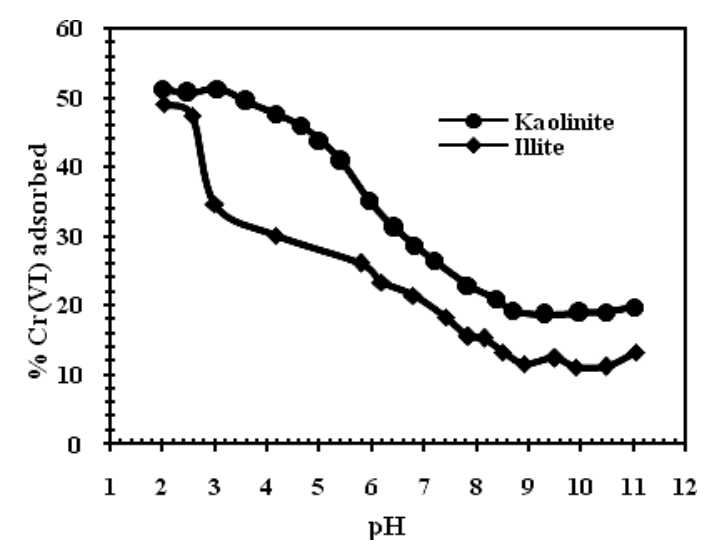

Figure 1. Effect of pH on the adsorption of hexavalent chromium onto kaolinite and illite.

neral can be protolyzed in two different ways, as oxide mineral surfaces [11-13]. First, in acid media, the surface may be protonated according to $\equiv \mathrm{SOH}+\mathrm{H}^{+} \Leftrightarrow \equiv \mathrm{SOH}_{2}^{+}$; Second, in alkaline solutions the surface hydroxyl groups can dissociate $\equiv \mathrm{SOH} \Leftrightarrow \equiv \mathrm{SO}^{-}+\mathrm{H}^{+}$. Therefore, the concentrations of surface species $(\equiv \mathrm{SOH}$ uncharged surface groups, $\equiv \mathrm{SOH}_{2}^{+}$positive charged surface groups, $\equiv \mathrm{SO}^{-}$ negatively charged groups) change at different $\mathrm{pH}$ values. With increasing $\mathrm{pH}$, the number of negatively charged $\equiv \mathrm{SO}^{-}$groups increases and this leads to the decrease of hexavalent chromium adsorption due to the electrostatic repulsion.

\subsection{Effet of Initial Concentration}

The content (\%) metal removal efficiency as a function of $\mathrm{pH}$ of the Kaolinite and Illite dispersions for various concentrations of hexavalent chromium is presented in Figure 2. The results indicate that the content removal of hexavalent chromium decreases as the initial concentration of hexavalent chromium increased. It was found that the adsorption of hexavalent chromium onto Kaolinite (Figure 2(a)) and Illite (Figure 2(b)) was strongly dependent on initial metal ion concentration and $\mathrm{pH}$ values. This discrepancy is explained by the saturation of the surface sites of Kaolinite and Illite by chromium.

At low initial hexavalent chromium concentrations, the available adsorption sites were easily occupied by hexavalent chromium resulting in higher removal efficiencies. However, as the initial concentration of hexavalent chromium increased, most of the available adsorption sites became occupied, leading to a decrease in the removal efficiency.

\subsection{Effet of Ionic Strength}

Adsorption of hexavalent chromium on Kaolinite and Illite as a function of $\mathrm{NaNO}_{3}(0.01,0.05$ and $0.1 \mathrm{M})$ concentration and $\mathrm{pH}$ of the solution $(2-11)$ is shown in

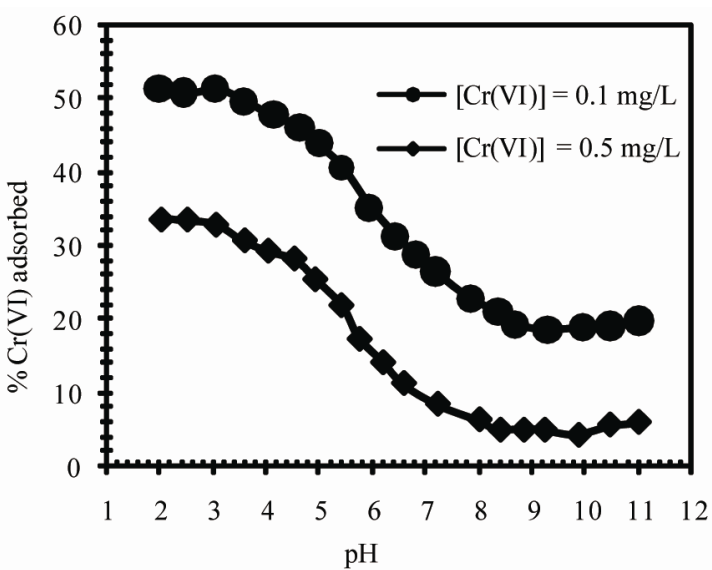

(a)

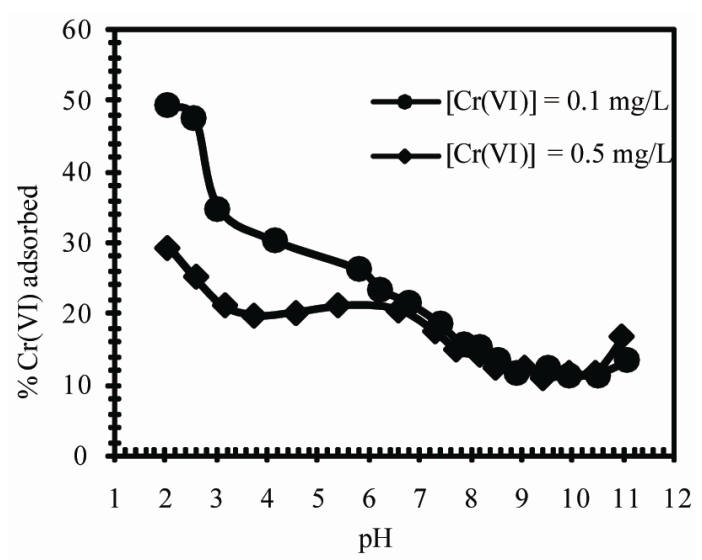

(b)

Figure 2. Adsorption of hexavalent chromium onto (a) kaolinite and (b) illite as a function of $\mathbf{p H}$ at different initial concentration.

Figure 3. The results showed that hexavalent chromium adsorption is strongly affected by ionic strength, especially at higher $\mathrm{pH}$ values.

It is somewhat surprising that increased ionic strength would result in increased anion adsorption. The possible explanation for the observed behavior is related to the surface charge characteristics of the clay mineral surface, specifically, the silanol groups of overall formula $(>\mathrm{SiOH})$ $[10,14]$ and the permanent negative charge. It is known that substitutions in the inorganic crystalline network, resulting in a negatively charged surface are independent of the physico-chemical conditions in the surrounding medium and that silanol groups have a low PZC (Point of Zero Charge), resulting also in a negatively charged surface. These negative charges would tend to reduce anion fractional uptake. At the higher ionic strength, more counterions (positively charged ions) would be attracted to the surface, thereby screening the negative surface charge more effectively and allowing more negatively charged 


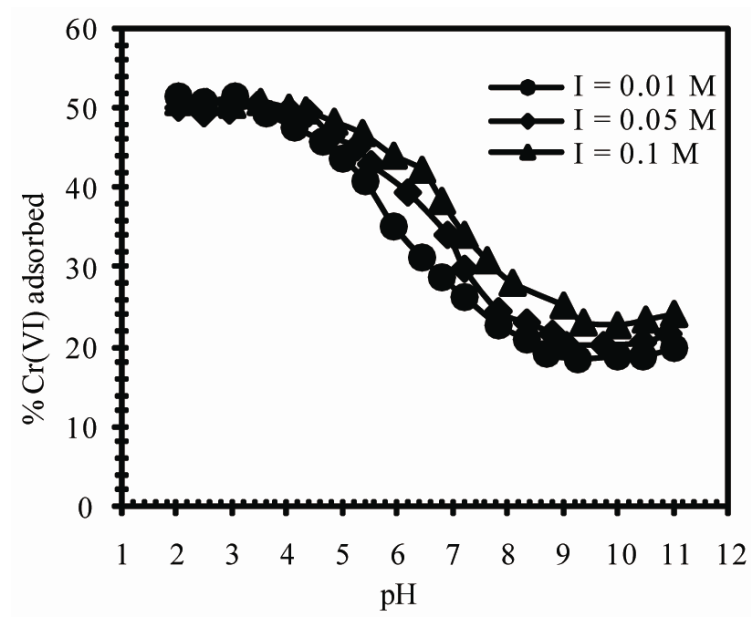

(a)

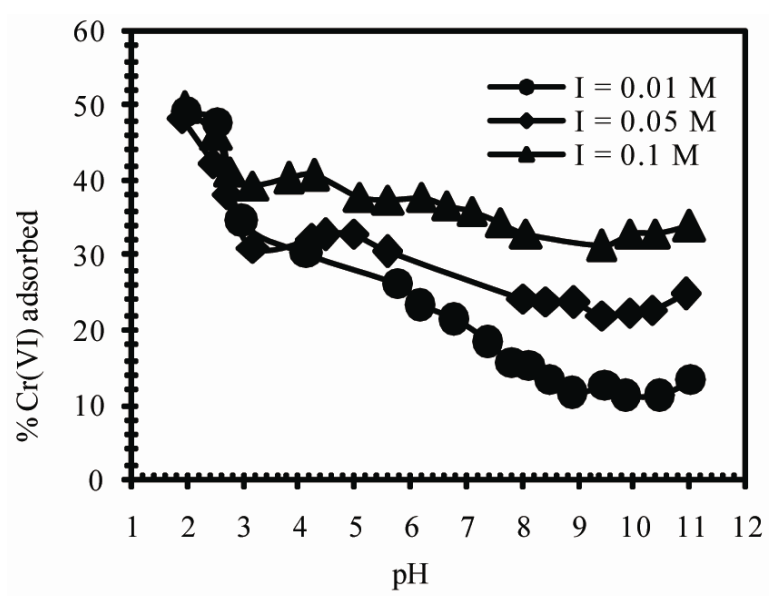

(b)

Figure 3. Adsorption of hexavalent chromium onto (a) kaolinite and (b) illite as a function of $\mathbf{p H}$ at different ionic strengths.

ions (anions) to adsorb.

As shown in Figure 3, one might argue that adsorption is increasing with increasing ionic strength at the higher $\mathrm{pH}$ region. This can be explained based on the above hypothesis. It is reasonable to assume that the effect would be more pronounced at higher $\mathrm{pH}$, where the negative charge of the mineral surface is higher. It is very pronounced for Illite (Figure 3(b)) and not very pronounced for Kaolinite (Figure 3(a)). This is not surprising if one considers the proportion of $\mathrm{SiO}_{2}$ present in the chemical compositions of the Illite (Table 1) and the most important properties of Illite is that they carry a large surface charge. This is a net negative charge and much of it is a permanent charge originating within the lattice structure by isomorphic substitution, which accounts for the cation exchange capacity (CEC) of Illite. Its value is very high when compared with Kaolinite [10].
Table 1. Chemical composition (in wt \%) of clay minerals.

\begin{tabular}{ccc}
\hline Elements & Kaolinite & Illite \\
\hline $\mathrm{SiO}_{2}$ & 45.6 & 53.9 \\
$\mathrm{Al}_{2} \mathrm{O}_{3}$ & 39.7 & 24.3 \\
$\mathrm{Fe}_{2} \mathrm{O}_{3}$ & 0.3 & 8.3 \\
$\mathrm{~K}_{2} \mathrm{O}$ & 0.9 & 6.5 \\
$\mathrm{MgO}$ & 0.1 & 4.0 \\
$\mathrm{Na}_{2} \mathrm{O}$ & 0.07 & 1.2 \\
$\mathrm{CaO}$ & 0.01 & 0.4 \\
\hline
\end{tabular}

\subsection{The Evaluation of Langmuir and Freundlich Isotherm}

In order to optimize the design of an adsorption system, analysis of the adsorption equilibrium data is important. Two isotherm equations namely the Langmuir and Freundlich isotherm models were tested for the adsorption phenomenon of hexavalent chromium onto Kaolinite and Illite.

The Langmuir model is valid for monolayer adsorption on a surface with a finite number of similar active sites $[15,16]$. The well-known expression of the Langmuir model is given by the following Equation:

$$
\frac{C_{e}}{q_{e}}=\frac{1}{Q \times b}+\frac{C_{e}}{Q}
$$

$C_{e}(\mathrm{mg} / \mathrm{L})$ is the concentration of adsorbate left in solution at equilibrium, $b$ is the Langmuir bonding energy coefficient, $Q(\mathrm{mg} / \mathrm{g})$ is the adsorption maximum, and $q_{e}$ $(\mathrm{mg} / \mathrm{g})$ is the amount of adsorbate adsorbed per unit mass of adsorbent.

The empirical Freundlich equation based on adsorption onto a heterogeneous surface $[15,16]$ is given below by the following Equation:

$$
q_{e}=K_{f} \times\left(C_{e}\right)^{1 / n}
$$

where $K_{f}(\mathrm{mg} / \mathrm{g})$ and $n$ are the empirical Freundlich constants characteristic of the system.

To gain further understanding of the behaviour and mechanisms involved in the Kaolinite and Illite hexavalent chromium interactions, the linearized Langmuir and Freundlich plots are studied as indicated in Figure $\mathbf{4}$ and Figure 5, repectively.

The values of parameters calculated from the slope and intercept of Figure 4 and Figure 5 are tabulated in Table 2. These data indicate that the correlation coefficients $\left(\mathrm{R}^{2}\right)$ for the Freundlich equation are slightly better than those for the Langmuir equation, closer to 1 . It suggests that there is not only single molecular layer adsorption, but also asymmetric adsorption on the adsorbent surface. Vázquez [17] suggested that the disagreement with the Langmuir model might be due to the heteroge- 


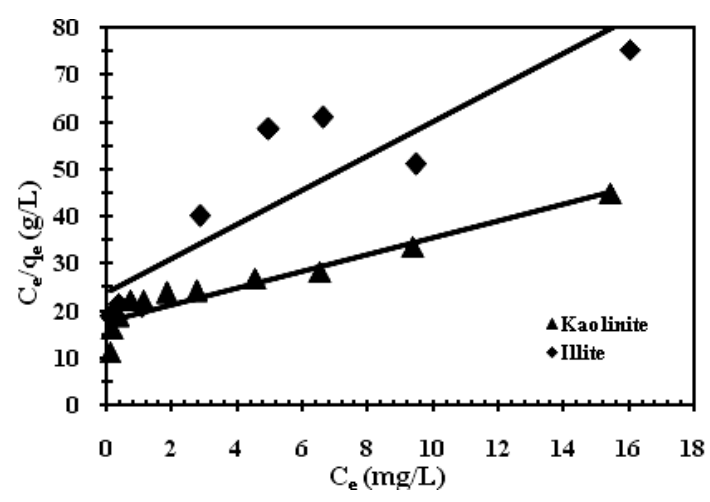

Figure 4. Langmuir isotherm plots for adsorption of hexavalent chromium onto kaolinite and illite.

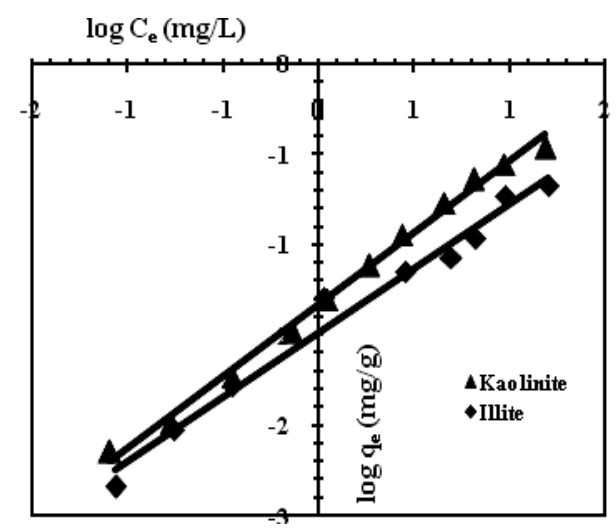

Figure 5. Freundlich isotherm plots for adsorption of hexavalent chromium onto kaolinite and illite.

Table 2. Constant parameters and correlation coefficients calculated for Langmuir and Freundlich adsorption models.

\begin{tabular}{ccccccc}
\hline \multirow{2}{*}{ Adsorbent } & \multicolumn{3}{c}{ Langmuir } & \multicolumn{3}{c}{ Freundlich } \\
\cline { 2 - 7 } & $Q(\mathrm{mg} / \mathrm{g})$ & $b(\mathrm{~L} / \mathrm{mg})$ & $\mathrm{R}^{2}$ & $K_{f}(\mathrm{mg} / \mathrm{g})$ & $n$ & $\mathrm{R}^{2}$ \\
\hline Kaolinite & 0.571 & 0.098 & 0.903 & 0.047 & 1.262 & 0.995 \\
Illite & 0.276 & 0.152 & 0.812 & 0.033 & 1.405 & 0.979 \\
\hline
\end{tabular}

neity of the adsorbent surface with resulting variation in adsorption energy. As has been observed by other authors $[18,19]$.

The magnitude of $n$ gives an indication of the favourability of adsorption. Values of $n$ larger than 1 show the favorable nature of adsorption. The value of $n$ (Table 2) suggests that hexavalent chromium is favorably adsorbed by the Kaolinite and Illite surface.

\section{Conclusions}

Kaolinite and Illite are found to able to adsorb hexavalent chromium from aqueous solution under various experimental conditions. The adsorption was found to be strongly dependent on $\mathrm{pH}$, initial hexavalent chromium concentration and ionic strength. The uptake of hexavalent chromium by Kaolinite and Illite was maximal at acidic medium, and remains significant for neutral $\mathrm{pH}$ values. Furthermore, the results obtained in this study showed good fits to the Freundlich adsorption isotherm, which could suggest a multi sites adsorption process. Even if Kaolinite and Illite are less efficient than iron oxides for the adsorption of hexavalent chromium, these adsorbents could be responsible of one part of the uptake of hexavalent chromium in sediments.

\section{REFERENCES}

[1] D. E. Kimbrough, Y. Cohen, A. M. Winer, L. Creelman and C. Mabuni, "A Critical Assessment of Chromium in the Environment," Critical Reviews in Environmental Science and Technology, Vol. 29, No. 1, 1999, pp. 1-46. doi:10.1080/10643389991259164

[2] J. Kotaś and Z. Stasicka, "Chromium Occurrence in the Environment and Methods of Its Speciation," Environmetal Pollution, Vol. 107, No. 3, 2000, pp. 263-283. doi:10.1016/S0269-7491(99)00168-2

[3] Agency for Toxic Substances Disease Registry (ATSDR), "Toxicological Profile for Chromium," Atlanta, 2000.

[4] World Health Organization (WHO), "Guidelines for Drinking-Water Quality," Incorporating 1st and 2nd Addenda, 3rd Edition, Vol. 1, Recommendations, Geneva, 2008.

[5] US Environmental Protection Agency (US EPA), "Guidelines for Water Reuse," Office of Wastewater Management Office of Water, Washington DC, 2004, EPA/R04/108

[6] Y. Xi, M. Mallavarapu and R. Naidu, "Preparation, Characterization of Surfactants Modified Clay Minerals and Nitrate Adsorption," Applied Clay Science, Vol. 48, 2010, pp. 92-96. doi:10.1016/j.clay.2009.11.047

[7] C. D. Palmer and R. W. Puls, "Natural Attenuation of Hexavalent Chromium in Groundwater and Soils," US EPA, Ground Water Issue, 1994, EPA/540/5-94/505.

[8] O. Ajouyed, C. Hurel, M. Ammari, L. B. Allal and N. Marmier, "Sorption of $\mathrm{Cr}(\mathrm{VI})$ onto Natural Iron and Aluminum (Oxy)Hydroxides: Effects of $\mathrm{pH}$, Ionic Strength and Initial Concentration," Journal of Hazardous Materials, Vol. 174, No. 1-3, 2010, pp. 616-622. doi:10.1016/j.jhazmat.2009.09.096

[9] B. Baeyens and M. H. Bradbury, "A Mechanistic Description of $\mathrm{Ni}$ and $\mathrm{Zn}$ Sorption on Na-Montmorillonite Part I: Titration and Sorption Measurements," Journal of Contaminant Hydrology, Vol. 27, No. 3-4, 1997, pp. 199222. doi:10.1016/S0169-7722(97)00008-9

[10] F. J. Huertas, L. Chou and R. Wollast, "Mechanism of Kaolinite Dissolution at Room Temperature and Pressure: Part 1. Surface Speciation," Geochimica et Cosmochimica Acta, Vol. 62, No. 3, 1998, pp. 417-431. doi:10.1016/S0016-7037(97)00366-9

[11] G. M. Beene, R. Bryant and D. J. A. Williams, "ElectroChemical Properties of Illites," Journal of Colloid and Interface Science, Vol. 147, No. 2, 1991, pp. 358-369. doi:10.1016/0021-9797(91)90168-8 
[12] T. H. Herrington, A. Q. Clarke and J. C. Watts, "The Surface Charge of Kaolin," Colloids and Surfaces, Vol. 68, No. 3, 1992, pp. 161-169. doi:10.1016/0166-6622(92)80200-L

[13] E. Tombácz, Z. Libor, E. Illés, A. Majzik and E. Klumpp, "The Role of Reactive Surface Sites and Complexation by Humic Acids in the Interaction of Clay Mineral and Iron Oxide Particles," Organic Geochemistry, Vol. 35, No. 3, 2004, pp. 257-267.

doi:10.1016/j.orggeochem.2003.11.002

[14] W. Liu, "Modeling Description and Spectroscopic Evidence of Surface Acid-Base Properties of Natural Illites," Water Research, Vol. 35, No. 17, 2001, pp. 4111-4125. doi:10.1016/S0043-1354(01)00156-7

[15] O. Mor, K. Ravindra and N. R. Bishnoi, "Adsorption of Chromium from Aqueous Solution by Activated Alumina and Activated Charcoal," Bioresource Technology, Vol. 98, No. 4, 2007, pp. 954-957. doi:10.1016/j.biortech.2006.03.018
[16] D. Q. L. Oliveira, M. Gonçalves, L. C. A Oliveira and L. R. G. Guilherme, "Removal of $\mathrm{As}(\mathrm{V})$ and $\mathrm{Cr}(\mathrm{VI})$ from Aqueous Solutions Using Solid Waste from Leather Industry," Journal of Hazardous Materials, Vol. 151, No. 1, 2008, pp. 280-284. doi:10.1016/j.jhazmat.2007.11.001

[17] G. Vázquez, J. González-Álvarez, A. I. Garcia, M. S. Freire and G. Antorrena, "Adsorption of Phenol on FormaldeHyde-Pretreated Pinus Pinaster Bark: Equilibrium and Kinetics," Bioresource Technology, Vol. 98, No. 8, 2007, pp. 1535-1540. doi:10.1016/j.biortech.2006.06.024

[18] J. M. Zachara, C. E. Cowan, R. L. Schmidt and C. C. Ainsworth, "Chromate Adsorption by Kaolinite," Clays and Clay Minerals, Vol. 36, No. 4, 1988, pp. 317-326. doi:10.1346/CCMN.1988.0360405

[19] S. Staunton and M. Roubaud, "Adsorption of 137Cs on Montmorillonite and Illite: Effect of Charge Compensating Cation, Ionic Strength, Concentration of Cs, K and Fulvic Acid," Clays and Clay Minerals, Vol. 45, No. 2, 1997, pp. 251-260. doi:10.1346/CCMN.1997.0450213 